\title{
Historias conceptuales
}

Enriqueta Lorena Cortés Manresa (D) https://orcid.org/0000-0003-2127-7802

Universidad de Guadalajara, México

lorenacortesmanresa@gmail.com

Guillermo Zermeño Padilla, Historias conceptuales, México, El Colegio de México-Centro de Estudios Históricos, 2017, 401 p.

Luego del impacto del "giro lingüístico", la “nueva hermenéutica” y las propuestas y hallazgos del grupo de investigadores que colaboraron en el proyecto "Iberconceptos" en 2009 y 2014 ; varios historiadores de América Latina han puesto mayor cuidado al léxico, sobre todo, se han interesado por los usos del vocabulario político en los procesos de modernidad que dieron sentido a la dimensión político-ideológica que configuró las identidades nacionales. En esta línea de investigación y reflexión se inscribe el reciente libro escrito por Guillermo Zermeño bajo el título Historias conceptuales.

En Historias conceptuales, la trayectoria académica de Guillermo Zermeño condensa el conocimiento resultante de una observación aguda y un trabajo minucioso de análisis a fuentes originales con una mirada distinta y profunda, que parte de las premisas de la semántica histórica en su vertiente hermenéutica y koselleckiana, y que da cuenta de cómo la experiencia de los hombres queda inserta en los conceptos que emplean en distintos contextos; en geografías y momentos históricos diversos. 
Varias son las reflexiones que encontramos en este volumen. Desde la crítica histórica, Zermeño analiza unidades conceptuales insertas en procesos de larga duración que organizan el discurso historiográfico occidental y muestran el estrecho vínculo entre estructura social y lenguaje. Compuesto por una erudita introducción y otros diez capítulos, en los que el autor nos ofrece un viaje por los conceptos de Espacio público, Historia, América/americanos, Libertad, Revolución, Civilización, Pobreza, Mestizo, Cacique y Caudillo, el texto presenta al lector, en palabras de su autor, la ventaja de ofrecer dos opciones de lectura: ser leído de continuo o por elección del concepto que capte su interés. El seguimiento de los itinerarios semánticos de los conceptos analizados responde a miradas de larga duración; varios tienen como punto de partida el siglo XVIII y, en algunos casos, se analizan hasta el siglo XXI (específicamente, el caso de pobreza).

La introducción lleva al lector a la reflexión sobre el concepto de modernidad, trasfondo en el que se resignifican los diez conceptos abordados. Para Zermeño la modernidad es un tipo de experiencia temporal, específicamente, la de la emergencia de un tiempo reconocido por los actores como nuevo, como "lo último", "lo actual”. Muestra que, de largo aliento, el concepto se ha reelaborado a través del tiempo y dicha transformación ha sido “mediada por el lenguaje y la cultura de cada época” (p. 25). Siguiendo a Hans Robert Jauss, considera que el estudio de este concepto debe considerar tres aspectos problemáticos: 1ํo Que no fue acuñado para nuestra época (actual); 2ํ․ Que pertenece a una larga tradición fundada en la distinción entre modernus y antiqui (propia de la antigüedad cristiana); y 3º. Que esta modernidad "generaría la necesidad de la construcción de un saber histórico para poder orientarse” (p. 26). La modernidad no es una, ni unívoca, son trayectos cualitativos más que un momento cronológico que señale su emergencia y su fin; son trayectos que corren paralelos 
en las vivencias de actores diversos y que se intersectan en determinados momentos históricos. La modernidad es, la creación de un vocabulario y la emergencia de la experiencia denominada moderna (p. 31).

Desde este enfoque, Zermeño se concentra en precisar una de las cuestiones centrales de la propuesta teórica de la semántica histórica, a saber, la distinción entre palabra y concepto; así, retomando a Koselleck y a Ritter señala: “un concepto es observable en el momento en el que una palabra singular adquiere la capacidad de designar un conjunto mayor de cosas y de operaciones” (pp. 32-33). En otras palabras, lo que Koselleck identifica como la atribución, a una palabra de uso cotidiano, de un grado mayor de generalidad descriptiva: los "singulares colectivos". Por ejemplo, la Historia con mayúscula, en cuyo concepto se contienen las múltiples historias; la Libertad, en la que están contenidas todas las libertades; la Revolución, en la que se conciben las características de todas las revoluciones; la Pobreza, que abarca en la mente de quien emplea el concepto, todas las condiciones que la connotan. La forma en la que los conceptos son resignificados depende del uso que los actores hacen de ellos, por ello, Zermeño también focaliza su mirada atendiendo la pragmática discursiva, tomando en cuenta los usos y sus contextos.

En el capítulo "Espacio público", Zermeño hace una lectura, revisión y crítica de las tesis habermasianas y de su adopción por diversos historiadores de Iberoamérica, y explora el potencial crítico del término en la nueva historiografía política. La potencialidad del término es vista en el uso de un modelo de análisis historiográfico centrado en la construcción del espacio público y los usos discursivos en que es tratado, lo que para Zermeño, ofrece la posibilidad de entender en forma más precisa la inserción de los países del área iberoamericana en las distintas modernidades que experimentaron analizando 
sistemáticamente el léxico empleado por los agentes históricos. Su reflexión historiográfica sobre el uso heurístico del término, le permite clarificar que el espacio público va más allá de la opinión pública, que no alude a un espacio físico limitado sino a su representación en “formas de comunicación que están entre ausentes, graduadas y reguladas por la comunicación escrita” (p. 62). Señala que una de las cuestiones fundamentales para el análisis y comprensión de estas formas de comunicación reside en repensar la teoría de modernidad, telón de fondo donde adquiere sentido la configuración del "espacio público”, considerando las distinciones "entre avance y retroceso, liberales y conservadores, tradicionalistas y progresistas" (p. 64).

En el capítulo dedicado al concepto de “Civilización”, Zermeño presenta el itinerario semántico de esta voz, desde fines del XVIII a los años setenta del siglo XIX. Detecta su uso como una forma de medir los avances de las naciones desde 1780 y describe cómo en los textos publicados en la época, se vincula su uso a los movimientos independentistas, vistos como logros de la civilización. En el seguimiento de la trayectoria semántica de civilización, concebida como un espacio para la creación y perfeccionamiento del hombre, identifica las intersecciones con los conceptos de nación y orden constitucional que configuran el imaginario de la legitimidad. Para el caso mexicano, Guillermo Zermeño señala que el año de 1825 es crucial para la transformación de la voz civilización y su fusión con el liberalismo, que el concepto se expande durante la década de 1840 y que hacia mediados de siglo comienza a asociarse con el término progreso. Luego del triunfo liberal, la novedad de su uso consiste en la profundización de la unión del término con el de progreso y se inscribe en un discurso evolucionista que parte de la premisa de que “cuanto más amigo de la libertad se sea, más se avanza en el camino de la civilización”. 
En cuanto al concepto de "Pobreza", los sentidos que se le han adjudicado son rastreados hasta el siglo XXI desde la antigüedad cristiana y medieval, cuando surge la distinción entre "trabajador pobre” e "indigente”, usos cuyos sentidos eran asociados a una vida virtuosa (pobreza ascética) o a una pobreza-castigo. Se alude a una muestra de la patrística eclesiástica, fuente básica para la reflexión sobre la pobreza; así como a las distinciones respecto a los términos egenus, pauper e indigente; y el vínculo entre “pobreza” y "caridad”. En este capítulo, Zermeño subraya la exigencia de considerar la relación del vocablo con las convenciones sociales que subyacen en su uso, por ello analiza en el discurso de actores de distintos momentos cómo visualizan, cómo definen, cómo experimentan la pobreza y qué características la connotan (p. 217). En el trayecto semántico de esta voz, identifica una mutación de sentido desde la segunda mitad del siglo XVIII, que deviene en la concepción de pobreza como problema social y asunto público y al mismo tiempo, encuentra cómo se devalúa el sentido de connotación moral. Su análisis de la voz, que lo lleva incluso al caso mexicano, revela el tránsito de una perspectiva que define la pobreza como condición social a otra que la define como problema social de interés del Estado.

Uno de los aspectos que se enfatiza a lo largo del volumen, para todos los casos, es el análisis de los usos de los conceptos desde una perspectiva sincrónica, lo que evita caer en anacronismos e interpretaciones que se alejan tanto del discurso como del pensamiento de los actores del pasado; además, añade y complementa a dicha perspectiva el enfoque diacrónico, lo que le permite hacer el recorrido del itinerario semántico de las voces analizadas y visualizar los deslizamientos semánticos.

La experiencia de la temporalidad de diversos actores, a través del uso de conceptos claves para la comprensión del complejo proceso de modernidad que vivieron, es lo que nos Secuencia. E-ISSN 2395-8464 
presenta Guillermo Zermeño. Su propia experiencia por estos senderos queda plasmada en esta muestra de Historias Conceptuales como una invitación a repensar la reflexión historiográfica desde este enfoque. 